\title{
Understanding Adult Learners as a Core Principle of Effective ESL-Educators
}

\author{
Natalia A. Biryukova ${ }^{1}$, Svetlana L. Yakovleva ${ }^{1}$, Tatyana V. Kolesova ${ }^{1}$, Larisa V. Lezhnina ${ }^{1} \&$ Alla A. Kuragina ${ }^{1}$ \\ ${ }^{1}$ Mari State University, Yoshkar-Ola, Russia \\ Correspondence: Natalia A. Biryukova, Institute of Pedagogy and Psychology, Mari State University, Lenin \\ square, 1, Yoshkar-Ola, 424000, Russia.
}

$\begin{array}{lcc}\text { Received: February 21, } 2015 & \text { Accepted: March 15, } 2015 & \text { Online Published: April 29, } 2015 \\ \text { doi:10.5539/res.v7n8p147 } & \text { URL: http://dx.doi.org/10.5539/res.v7n8p147 }\end{array}$

\begin{abstract}
The article deals with a comparative analysis and practical application of Russian and foreign experience connected with some important aspects of teaching English to adult learners who are more problem centered than subject centered in learning. It is shown that the learning process will be successful in case it is based on such andragogical principles as the identification of adults' individual difficulties and educational experience; content of teaching meeting their objectives and needs; use of interactive methods of teaching; integration of individual and group forms of learning activities and establishment of connection between adults' life and work experience in the process of learning when a ESL instructor is not only an expert but a facilitator. In addition, barriers and motivation, interactive teaching strategies and technologies of practice-oriented approach have been studied in the article.
\end{abstract}

Keywords: adult learners, teaching English as a second language, andragogical principles, content of teaching, practice-oriented approach, interactive methods, facilitator

\section{Introduction}

An intensive development of international cooperation requires active foreign language mastery from all modern specialists. An increased status of a foreign language is currently explained by the expansion of economic, political and cultural links between countries; development of mass communication media; expansion of working power migration; intergovernmental integration in education; wide access to high-quality education in one's country and abroad. Hence, great numbers of adults make efforts to continue their education while continuing to study a foreign language even at their mature age.

In Russia, teaching adults English is one of popular directions of formal (additional professional) as well as of non-formal (hobby-programmes) education. This is due to a number of reasons connected with uniqueness and significance of English in the world community. Being the language of the Internet, international cooperation and interaction, English is a universal source of information and communication. Increasing school children, students, teachers and specialists' exchanges in the framework of international programmes made English an irreplaceable agent of these activities. As a result of increased overall population mobility and increasing of working power migration, English has become the instrument of social and economic adaptation of people, the guarantor of their professional growth.

Today English like no other academic subject facilitates the culture of communication. In the process of education adults learn to be speech partners, study different communication techniques, master speech etiquette, strategy and tactics of dialogue and group interaction. They learn to show initiative, be benevolent and tactful which in turn are professionally significant qualities of any specialist. "A foreign language is the only subject that makes it possible to teach an adult the culture of speech communication directly" (Zimnyaya, 1998, p. 32).

Success in teaching adults a foreign language is in many respects determined by understanding features of adults as learners, ability to predict and identify their difficulties in educational process. However, in contemporary Russian practice of teaching English diagnostics, prediction and correction of difficulties of different levels and kinds are still insufficiently developed. ESL-teachers are constantly searching for technologies providing effective mastering of a foreign language by adults which are directed to self-development of a learner's personality in the process of overcoming difficulties. 


\section{Hypothesis and Methods}

Hypothesis of the research: teaching adults a foreign language will be successful if the learning process is based on the key andragogical principles: individual difficulties and educational experience of adults are identified and taken into account; the content of teaching satisfies the goals and needs of adult learners; instructors use interactive methods of teaching and integrate individual and group forms of learning.

Research Methods. Theoretical analysis of the literature in psychology and education relevant to the research topic; comparative analysis of Russian and foreign experience in teaching adults foreign languages; methods of psychological and educational assessment: interviews, questionnaires, tests, direct and indirect observation, self-evaluation and education practitioner-led evaluation; statistical analysis of the obtained data; summary of the research outcomes taking into account new facts and specific conditions; development and implementation of a model of teaching adults a foreign language in compliance with the key andragogical principles.

\section{Results and Discussion}

\subsection{Adult Learner \& Adult Theory}

There is still no entirely unified viewpoint about the definition of adult learner in American theoretical and practical studies.

Darkenwald \& Merriam (1982) define an adult learner as "a person that has taken on his/her socially significant roles and is apt to accepting responsibility for his/her life" (p. 132). Alen Knox (1987) gives the following definition: "An adult learner is a man or a woman, 23 years of age or older who works full time while enrolled in education course and has dependents" (p. 85).

Overstreet (2007) stresses, that an adult is not the person who knows a lot but the one who applies the knowledge gained a wise way thus featuring personal development. Therewith all adults tend to be first of all, autonomous, self-directed and goal-oriented. They are also demanding and motivated to gain significant knowledge. They know what they want and favour the possibilities for practical application of the knowledge gained. Adults have established views on many issues that in most cases cannot be dismissed and must be respected. They are able to discuss and critically assess the information. In addition adults have accumulated life experience in diverse areas which enables them to draw on their prior skills and knowledge while learning.

Knowles (1984) made a more detailed definition of an adult. As it is follows from his definition an adult is "a person that behaves as an adult, i.e. starts performing adult-like roles (full-time worker, spouse, parent, participating citizen, soldier, etc) and when develops a concept of being responsible for his/her own life".

Andragogy is a methodological basis of teaching a foreign language to adults. The term belongs to Malcolm Knowles who emphasized that adults learn differently from children and that educator of any kind should use a different approach to facilitate their learning. In contrast to pedagogy which means teaching children, andragogy encourages teachers to use special technologies and strategies distinguishing adults from children.

In 1970, Malcolm Knowles presented his ideas in "The Modern Practice of Adult Education: Andragogy Versus Pedagogy", where the following peculiarities of teaching adults were described:

1) A leading role in learning belongs to an adult.

2) An adult learner consciously endeavours to self-realisation, independence and self-government.

3) An adult leraner has life (domestic, social and professional) experience which may be used both in his teaching and in teaching of his colleagues.

4) An adult learner studies to solve his vital problems and achieve his aims.

5) Adults expect speedy implementation of their knowledge, experience and skills that they have developed during learning.

6) Education of an adult is largely determined by temporal, spatial, professional and social factors either limiting or contributing to the process of learning.

7) Education of an adult should be organized as a joint activity of an educator and an adult in all its stages: diagnostics, planning, realization, evaluation and correction of the results (Merriam et al., 2007).

In Russian education the understanding of methodological foundations of teaching adults is associated with the research and publications of the Institute of Adult Education of the Russian Academy of Education (Saint-Petersburg): Sergey G. Vershlovsky (2002), Irina A. Kolesnikova (2003), Viktor G. Onushkin (1997). The ideas put forward by these researchers have constituted the foundation of the current stage in the development of 
adult education in Russia. Moreover, the principles of teaching adults developed by the representatives of this scientific school have a lot in common with the andragogical principles put forward by Malcolm Knowles and his followers.

The Russian researchers have formulated and substantiated the following principles of teaching adults:

1) For creating a learning environment for a positive adults' self-actualisation it is necessary to create a situation of "living" that is a model in the course of teaching situations that allow learners recognizing their personal values, and emotionally "experience" them in the process of learning. Hence, establishment of connection between adults' life and job experience and the learning process is of high importance.

2) Use of active forms of teaching. Adults "stick" to their stereotypes until in the course of doing activities they recognize the necessity and efficiency of renouncing a few of them. Active teaching, especially group work, is necessary to be used for this purpose. Small-group work provides teachers with the opportunity to create conditions favourable for efficient joint activities performed by adult learners who have diverse life and work experience, psychological characteristics and educational needs.

3) Reflexive accompaniment of the progress and the outcomes of the learning process. Empirical knowledge suggests that adults have difficulties with analyzing their professional and educational activities. Instead of reflecting on their own actions they analyze the situation, which is accompanied by high emotional stress. While being taught methods of reflexive accompaniment learners start looking for the "internal" reasons for their failures.

4) Consistency of communicative cultures. Adults who join a course have diverse communicative subcultures caused by their previous professional and life experience. Only a developed communicative culture makes it possible for learners to do joint activities in a dialogue mode. The analysis of specific situations of interaction, which are meaningful for adults, is an important method of teaching the rules of efficient communication.

5) Use of a modular principle of the learning process organisation. The implementation of this principle provides teachers with the opportunity to be flexible in creating the models of teaching which can be as close as possible to the needs of specific categories of learners or can be adjusted to the changes in the needs of adult learners (Biryukova, 2010).

The above formulated principles do not contradict with the traditional didactic principles. They partly develop them, partly correlate with them. In real teaching practice it is impossible to find a situation in which andragogical learning model and its principles would be applied completely and fully. The objective is not to reject the pedagogical model but rather gradually apply more and more andragogical principles as learners grow up.

\subsection{Barriers and Motivation}

Adult learners have their own background, perception of the world, where they have to survive and succeed in their personal endeavours. Internal and external factors influence adult learners both in their past and present experiences form these views. This perception in its turn shapes adult learners' motivation and sets barriers to learning.

There are many reasons why adults take part in different educational programmes. Merriam, et al. note that the majority of them-90.6\% - participate because of career/job reasons (Merriam et al., 2007).

Becoming a student for some adults means facing significant changes in their already complicated and intensive life. It is a sort of a turning point when an adult learner considers all pros and cons of the decision made by asking the following questions: "Is it the right decision to start learning again? How much time and efforts will I have to contribute? Will I manage to cope with this extra load? What advantages will the education provide? How will it change my life?" Thus adults start learning. Most of them (80-90\%) learn to use the new knowledge further in their career. The process of learning itself as a pleasant activity doesn't represent any practical value. Of course some individuals are attracted by interpersonal communication while learning, others - by cognitive satisfaction. But the key feature of the learning process is the fact that learning is not an ultimate goal for adults but a means to achieve their personal or professional goals.

In 2012-2014 a study was carried out to evaluate motivation of adults studying English at the Mari State University in the program "English without Barriers". The survey covered 150 respondents and was also aimed at the identification of the barriers that adults face during studying a foreign language.

The results showed that the key rationale for adults to study a foreign language is practical application of language skills in professional activities, as well as in everyday life. The practical focus of the respondents' 
motivation is evidenced by the fact that only $8 \%$ of them chose all-round development to be the reason for studying a foreign language. Their main motives were ranked in the following order from the top to the bottom one: a desire to communicate with native speakers, cooperation with international colleagues, passing a test or an exam, a trip abroad, an opportunity to get information from various foreign-language sources (press, TV, the Internet), a desire to read foreign literature in the original, all-round development (Biryukova, 2014).

The respondents consider that the key barriers to gaining a foreign language competence are: a lack of free time, since an adult has to combine studies with performing job and family duties (87\%); an age barrier-vacancy of thought, stereotypes related to activities, such complexes as "It is too late for me", "I feel ashamed", etc- ( $81 \%)$; a gradual loss of aptitude for learning (45\%); taking the role of a student that is perceived to be irrelevant to the current status (27\%); physical health (4\%).

The analysis of the observation and the questionnaire results as well as the participants' oral responses showed that in the course of studying a foreign language adults face difficulties related to: listening comprehension (63\%); communication - cannot introduce themselves, start and maintain a conversation, gain the interlocutor's interest, interrupt a conversation politely, say goodbye (57\%); express thoughts in a foreign language (41\%); study grammar (34\%); translate texts (32\%); memorize vocabulary and verbal clichés $(17 \%)$; spelling (14\%); work in a team $(6 \%)$.

The participants gave the following responses to the question "The development of what skills (listening, speaking, reading, and writing) causes you fewer difficulties?" $56 \%$ can easier do receptive language activities, $93 \%$ of them have fewer difficulties with reading (it is possible to go back to the sentence which causes difficulties and look up an unfamiliar word in a dictionary), 7\%-with listening (well-developed phonemic hearing); $46 \%$ consider productive language activities to be easier for them to fulfill: $68 \%$ have fewer difficulties with speaking since it involves improvisation and selection of the most suitable lexical units, besides, a person has the opportunity to think over his/her response, $32 \%$-with writing due to the possibility to work with a dictionary, correct the written part, and carefully think over an appropriate and a most accurate way to communicate ideas.

Both receptive and productive language activities can at the same time cause great difficulties. $70 \%$ of the respondents consider listening to be the most difficult, which is linked to the problems of perceiving information by ear, a bad phonemic hearing. It often happens that a person focuses on a word (phrase) and loses the meaning of what he/she hears. 50\% have difficulties with speaking a foreign language, as it is hard for them to find a word or phrase necessary to express their thoughts and it is not easy for them to switch from one language to the other while speaking. $30 \%$ find writing to be difficult, which is connected with poor visual memory and orthographic literacy. $10 \%$ of the respondents have problems with reading, which is caused by phonetic difficulties and poor knowledge of the rules of reading.

The participants gave the following responses to the question "What do you aspire to be able to do after doing the course in the English language?" $70 \%$ - speak a foreign language, $15 \%$ - correspond, $9 \%$-read and translate special literature, $6 \%$ - listen to music, watch movies and TV programmes in a foreign language.

The most typical discrepancies between the needs and expectations of adult learners and the reality were identified in the course of studying organisational and methodological aspects. Based on the results of the observations it has been determined that lessons with adults are mostly conducted in accordance with formal principles: a teacher communicates ready-made knowledge, which is later consolidated by means of involving learners in doing reproductive exercises. It hinders the development of students' pro-active attitude and speaking skills. $85 \%$ of the respondents preferred to study in a group, where lessons are held in a lively atmosphere with easy communication and creative tasks, and only $15 \%$ chose the traditional way of studying where a teacher is first of all "the source of knowledge". The responses (75\%) also testify that there is no variety in methods of teaching. Educators usually use the frontal instruction method- $\rightarrow \mathrm{P} 1, \mathrm{P} 2, \mathrm{P} 3$, that is teacher-pupil. However, the respondents expressed a desire to work in pairs (47\%), in small groups (36\%), all together in a group (17\%).

Thus, the difficulties that adults face during studying a foreign language are both intrinsic and extrinsic. An effective ESL educator should take into account these two groups of factors affecting motivation and thus creating barriers to learning. Understanding which factors are intrinsic and which are extrinsic enables us to focus on the root cause of the problem. It further allows an ESL teacher gaining a better understanding of an adult learner and finding ways to motivate them and eliminate their barriers to learning.

Adults' involvement in the process of studies is considered to be an indicator that adult learners have overcome their difficulties (Biryukova \& Filatova, 2007). Personal involvement is a manifestation of the motive of personal development. On the one hand, while promoting this position an educator changes his/her attitude 
towards teaching; the content of education (new knowledge, skills and abilities) is perceived as a source of enhancing learners' potential for creativity, which also influences the process of renewing the system of the inner world. On the other hand, it facilitates teaching interpersonal interaction in the system of social relations. All the above mentioned contributes to the development of a positive emotional attitude to the whole process of studying, since any personal experience even problems and difficulties, that arise in the course of learning a subject or in social relations, can be used by learners as an additional situation for challenging oneself, a situation motivating for further self-knowledge and self-development.

The results of the research suggest that personal involvement in the educational process is determined by a system of interrelated factors:

- A positive attitude of learners towards the content of education, where the attitude is generally determined by the learners' attitude to their professional activities, as well as their cognitive interests;

- A positive attitude to the teacher and other learners;

- A positive attitude of learners to themselves as developing personalities, which is an indicator of a person's aim for self-development.

Wlodkowski stresses that adults want to be successful learners. But there might be different reasons which can have a negative impact on adults' motivation. If adults have a problem with success their learning motivation will usually decline (Wlodkowski, 2008). Adult learners often have a practical mindset when choosing to participate in educational programmes, and they often expect to experience success.

\subsection{Teaching Strategies to Help Adult ESL-learners}

The goal of ESL classes is the development of students' "communicative competence". Communicative competence involves the ability to correspond with a native speaker in a real-life situation based on real-life communication techniques than on knowledge of grammar rules. Communicative competence includes the following:

- Grammatical competence - accutare usage of vocabulary, grammar, pronunciation, spelling and word formation;

- Sociolinguistic competence - knowledge of speech acts and functions such as persuading, apologizing and describing;

- Discourse competence - the ability to combine ideas to achieve cohesion in form and coherence in thought.

In order to achieve this goal ESL instructors should understand how adults learn and apply appropriate learning strategies/methods that accommodate adults as learners. "The purpose of teaching is to facilitate personal growth that influences professional, social, and political aspects of adult learners" (Galbraith, 2004, p. 3). It is impirtant that all teaching strategies should be designed and implemented from an adult perspective.

Practice-oriented approach. Specificity of adult didactics becomes apparent in special selection of its content to be studied. The research aiming at the detection of adult learners' satisfaction with their education show that the reason of their dissatisfaction frequently lies in similar instructions used at their secondary school and university (Yakovleva, 2013). Learning content for adults should meet their needs, excite their interest, encourage their studying and facilitate self-development of their personality. While designing the course of a foreign language one must bear in mind that its content is to be based on the comprehension of the learner' s reasons and goals for studying.

The best means of teaching a foreign culture are authentic texts in case they reveal national identity and illustrate the language operation in the form acceptable for its native speakers in spontaneous social context. Authenticity promotes increase in the learner's motivation and creates conditions for a more effective immersion into the language environment.

Introduction of interactive methods of teaching. Russian scholars B. P. Esipov, Sh. I. Ganelin, I. Y. Lerner, M. I. Makhmutov note that teaching can be implemented actively and passively.

In case of passive teaching a learner performs the role of an object: he/she is to acquire and reproduce the information being communicated to him/her by a teacher or some other source of knowledge. Learners in this case, as a rule, neither cooperate with each other nor do any problem-solving tasks.

In case of active teaching a learner becomes the subject of his/her learning activity, enters the dialogue with his/her teacher, takes an active part in the cognitive process while performing creative and problem-solving tasks. 
One of the current methods of active teaching is interactive teaching. This is a method of "teaching being based on a learner's interaction with his/her learning environment, learning medium" (Kolesova, 2011). Using interactive methods of teaching instructors involve learners in the educational process where they communicate with each other, exchange information, solve problems, simulate situations, evaluate their groupmates' actions and their own behaviour, immerse themselves in the atmosphere of business cooperation while solving problems. Interactive teaching is being implemented under constant change of activity types: playing, discussion, working in small groups.

Forms and methods of interactive teaching can be subdivided into:

- Discussion-oriented: dialogue, group discussion, real life situation analysis, moral choice situation analysis, etc.

- Game-based: didactic and creative games, as well as business and role plays;

- Training (communication trainings and sensitive ones).

Interactive teaching methods enable instructors to intensify the process of learning a foreign language by adult learners. Yakovleva (2013) considers that if interactive methods are applied regularly, learners develop productive approaches to acquiring information, they lose their fear of making incorrect assumptions (since a mistake does not entail any negative estimation) and establish trust relationships with their teacher. In the process of interactive learning everybody is successful, everybody makes his/her own contribution to the overall result of the group work, and the process of learning becomes more conscious and fascinating. The learners' knowledge and experience which they share serve as a source for their own enrichment. While sharing their knowledge and experience the participants fulfil some teaching functions of their instructor which increases their motivation and facilitates more efficient learning.

Evidence suggests that the development of interactive methods of teaching is to a large extent determined by its link to information technologies. It is no coincidence that the term "interactive teaching" is mentioned in connection with electronic education (e-learning), distant education, the use of Internet resources as well as electronic textbooks and reference books, on-line learning. With the help of multimedia, video projectors, electronic screens and networks there appear new opportunities for mass and more effective language learning, connected with the organization of a foreign language environment and visualization of physical or information objects of the language.

The implementation of interactive methods of teaching indicates that we are dealing with a student-centered approach. Consequently, the paradigm of "computer-learner" provides the learner with the freedom of choice and decision making in the educational process. The learner should personally understand, according to what strategy he/she prefers. J. Rubin and I. Thompson (Sanchez, 2006, p. 360) considered in this case, several possible strategies: "show some awareness", "will organize their own learning", "be creative", "learn to cope with uncertainty", "learn from your mistakes", "use context".

The integration of individual and group activities. Adults study a foreign language in groups as well as individually. Group work facilitates the creation of an atmosphere of mutual support. While doing group work adults use their personal and professional experience. In the process of teaching adults different forms of group interaction can be successfully used: pair work, three-four people group work, two big teams work.

Empirical knowledge suggests that individual process of knowledge acquisition is more efficient when learners do a common communicative task. A joint activity turns into close cooperation which results in establishing relationships of mutual responsibility for successful implementation of the task. When learners are given individual tasks they work independently from the others. The value of this mode is in assuring active involvement of each learner into studying and enabling an adult learner to work in the mode according to his/her abilities. A teacher gets an opportunity to differentiate tasks taking into account individual characteristics, needs, interests of adults. Individual mode of learning a foreign language can be applied when adults work with new vocabulary, read and translate subject-oriented texts, work with newspaper and journal articles.

Game-based teaching. The use of game-based teaching methods increases the effectiveness of adult education because a game involves learners into cognitive activity; learning through play is being done by means of the learners' own activity; a game is a free activity providing its participants the opportunity to make a choice, express, develop and gain knowledge about oneself; a game creates a comfortable atmosphere at the lesson and motivates learners to study. A game helps to create the atmosphere of communication in a foreign language, establish new emotional and communicative relationships based on interaction, as well as decrease emotional tension of adult learners.

For teaching adult learners a foreign language role-playing games being used for simulating real situations of 
communication are very important (Lezhnina, 2013). In learning a foreign language through role playing enhancement of speech skills takes place. Being a model of interpersonal communication role-playing causes the need in communication while providing personal and cognitive activity of learners. Being involved in role-playing participants begin to interact; role-playing involves absolutely everybody into activity. A most important element of role-playing is the situation as an imaginary moment of real activity where speech behaviour of interlocutors in their typical social and communicative roles is realized. These roles are of conventional character. Moreover, role playing certain situations the participants have an opportunity to prepare themselves for similar situations in real life.

The position of a teacher. The success of educational process in many respects depends upon a teacher' $s$ personality, the level of his/her competence, skills of using methods of teaching as well as his/her position.

We distinguish two basic positions of the teacher of adult learners: an expert and a facilitator. The aim of the teacher-facilitator is to facilitate the development and personality growth of an adult learner. According to Carl Rogers, the most important characteristics of the facilitator are empathy, absolute approval of the learner's personality, authenticity. The task of the facilitator is to direct the process of information exchange between the participants of interaction. Biryukova \& Filatova (2007) consider that specific character of activity of the teacher-facilitator is determined "not only by the age of the contingent he/she is working with, but the aim of his/her activity" (p. 58). The teacher-facilitator appeals to the participants' personal experience, develops their activity, combines theory with practice, supports the multiplicity of viewpoints, relies on mutual enrichment and understanding of the participants.

The position of the expert in educational process is a "traditional", subject-object position of the teacher. His/her task is to provide the learners with information, design and direct their activity. The teacher-expert knows teaching methods, achieves success in reaching his/her objectives, and relies on teaching ready linguistic clichés. However, his/her adult learners are as a rule passive, they are getting tired of monotonous tasks and do not agree with the views being imposed to them.

Indicators of the right position and teaching strategy for a teacher in adult education are: openness and trust of adult audience; high scale of inclusiveness of the learners into work; constancy of cognitive activity of learners; sincere address of the learners to each other and their teacher for help; presentation of individual issues for cooperative discussion at the lessons; free presentation of one's own position; wish to consider their teacher' s opinion (Biryukova, 2007).

Getting to know adults' abilities, experiences and motivation can be accomplished by interviews, tests, simulations, any exercises to help us understand our 'non-traditional' learners. Such methods and techniques can help to develop the learning environment and inrich the motivation of adults through building their self-identity (Knowles et al., 2005, pp. 66-67). It is evident that the teacher playing a great role in the process of education is perceived by learners as the key to their further professional growth and success. It is his/her professional competence that effectiveness of overall educational process is dependent from. Hence, the main task of a teacher is to help the learner to find and effectively use his/her own learning style, reveal his/her potential and individuality.

\section{Conclusion}

The development of international cooperation in various spheres of human life results in the necessity for people to be fluent in foreign languages. While mastering a foreign language, adults consciously set themselves a significant goal of developing foreign language skills in order to increase their competitiveness as well as the possibilities for such interaction as "I and the world." Therefore, the research related to increasing the effectiveness of teaching a foreign language in continuing education is currently topical.

During the pilot project conducted at the Mari State University, the effectiveness of teaching adults a foreign language was achieved by taking into account individual difficulties and educational experience of adult learners; introducing practice-oriented course content that conformed to the goals and needs of adult learners; integrating individual and group forms of learning activities; as well as implementing interactive methods of teaching. Implementation of the abovementioned activities made the process of learning English more comfortable for adults: they managed to get rid of their fear of negative evaluation, gained self-confidence, mastered a significantly larger amount of material and improved its understanding; increased their cognitive activity and independence; changed the way they used to interact with each other; group cohesion has also increased. A new position of adult learners - active subject of communication in a foreign language - contributed to the development of their communicative competence. The success achieved by adult learners stimulated their activity and provoked steady interest in the language, which stimulated the need for their self-development. 


\section{References}

Biryukova, N. A. (2010). Implementation of Andragogical Principles of Teaching Adults in the Field of Continuing Education. Siberian Journal of Education, 15, 4-9.

Biryukova, N. A. (2013). University as a Center of Supplementary Adult Education: The USA Experience. In K. Reiss (Ed.), Transformation of Approaches to Education in Regions of the World: Experience of Russia, CIS states, Europe states and the USA (Vol. 1, pp. 41-54). New York: CIBUNET Publishing.

Biryukova, N. A. (2014). Teaching Students a Foreign Language in the Context of Internationalisation of Higher Education. Noviy Universitet, 7(40), 19-23. http://dx.doi.org/10.15350/2222-1484.2014.7.0004

Biryukova, N. A. \& Filatova, A. V. (2007). Teaching Adults: Theory and Practice of Andragogical Support. Yoshkar-Ola: Mari State University.

Brookfield, S. D. (1986). Understanding and facilitating adult learning: A comprehensive analysis of principles and effective practices. San Francisco: Jossey-Bass.

Darkenwald, G. G., \& Merriam S. B. (1982). Adult education: foundations of practice. N. Y.: Harper Collins.

Finn, D. (2011). Principles of Adult Learning: An ESL Context. Journal of Adult Education, 40(1). Retrieved from https://www.questia.com/library/journal/1P3-2569072221/principles-of-adult-learning-an-esl-context

Galbraith, M. W. (2004). The teacher of adults. In M. W. Galbraith (Ed), Adult learning methods: A guide for effective instruction (3rd ed., pp. 3-21). Malabar, FL: Kriegar.

Knowles, M. (1970). The modern practice of adult education-Andragogy versus pedagogy. New York: Association Press.

Knowles, M. (1984a). Andragogy in Action. San Francisco: Jossey-Bass.

Knowles, M. (1984b). The Adult Learner: A Neglected Species (3rd ed.). Houston: Gulf Publishing.

Knowles, M. S., Holton, E. F., \& Swanson, R. A. (2005). The adult learner: The definitive classic in adult education and human resource development (6th ed.). New York: Elsevier.

Knox, A. B. (1987). Adult development and learning. San Francisco: Jossey-Bass.

Kolesnikova, I. A., Maron, A. E., \& Tonkonogaya, E. P. (2003). Fundamentals of Andragogy: Textbook for students of higher teachers' training institutions and others. Moscow: Academiya.

Kolesova, T. V. (2011). Use of Didactic Capacities of ICT for Motivation of Studying English at University. Bulletin of Mari State University, 7, 136-139.

Kolesova, T. V., \& Komelina, V. A. (2012). Use of Information Technologies in Educational Process of Higher Education Institutions while Delivering a Course "Foreign language". Yoshkar-Ola: Mari State University.

Lee, C. (1998). The Adult Learner: Neglected No More. Training, 35(3). Retrieved from http://eric.ed.gov/?id=EJ560475

Lezhnina, L. V. (2012). Fundamentals of Developmental Psychology. Dushanbe: Russian-Tajik Slavonic University.

Merriam, S. B., Caffarella, R. S., \& Baumgartner, L. M. (2007). Learning in adulthood: A comprehensive guide. San Francisco: John Wiley \& Sons, inc.

Merriam, S. B., \& Brockett, R. G. (2008). The profession and practice of adult education: An introduction. San Francisco: John Wiley \& Sons, inc.

Onushkin, V. G. (Ed.). (1997). Theoretical Framework for Continuing Education. Moscow: Pedagogica.

Orem, R. A. (2005). Teaching Adult English Language Learners. N. Y.: Krieger Publishing Company.

Sanchez, A., \& Barreiro, J. M. (2006). Design of Virtual Reality Systems for Education: Cognitive Approach. Educucation and Information Technologies, 5(4), 345-362. http://dx.doi.org/10.1023/A:1012061809603

Skilled Immigrants: A Toolkit for ESL Practitioners. Chapter Three: Adult ESL Classroom Strategies and Lesson Ideas. Retrieved from http://www.globaltalentbridge.org/toolkit/pdf/CH3_ESLStrategies.pdf

Vershlovsky, S. G. (2002). Adult Education: Experience and Problems. Moscow: Znaniye.

Vorobyev, V. F., Ivanova, V. V., \& Lezhnina, L. V. (2013). Innovative Methods of Education: Theory and Practice. Saint-Louis, MO, USA: Publishing House Science \& Innovation Center. 
Wlodkowski, R. J. (2008). Enhancing adult motivation to learn: A comprehensive guide for teaching all adults (3rd ed.). San Francisco: Jossey-Bass.

Yakovleva, S. L. (2013). Express Yourself Through Writing and Speaking. Yoshkar-Ola: Mari State University.

Yakovleva, S. L. \& Fliginskikh, E. E. (2013). Non-imitational Active and Interactive Forms in Teaching Linguistic Subjects at University. In K. Reiss (Ed.), Transformation of Approaches to Education in Regions of the World: Experience of Russia, CIS states, Europe states and the USA (Vol. 1, pp. 198-212). New York: CIBUNET Publishing.

Yakovleva, S. L., \& Pershina, M. A. (2013). Imitational Active and Interactive Forms in Teaching English at University. European Social Science Journal, 9, 111-121.

Zimnyaya, I. A. (1998). Psychological Aspects of Teaching Speaking in a Foreign Language. Moscow.

\section{Copyrights}

Copyright for this article is retained by the author(s), with first publication rights granted to the journal.

This is an open-access article distributed under the terms and conditions of the Creative Commons Attribution license (http://creativecommons.org/licenses/by/3.0/). 